\title{
The Phosphodiesterase 8B Gene rs4704397 is Associated with Thyroid Function, Risk of Myocardial Infarction, and Body Height: The Tromsø Study
}

\author{
Rolf Jorde, ${ }^{1-3}$ Henrik Schirmer, ${ }^{3}$ Tom Wilsgaard, ${ }^{4}$ Ragnar Martin Joakimsen, ${ }^{1-3}$ Ellisiv Bøgeberg Mathiesen, ${ }^{3,5}$ \\ Inger Njølstad, ${ }^{4}$ Maja-Lisa Løchen, ${ }^{4}$ Yngve Figenschau, ${ }^{1,6}$ Johan Svartberg, ${ }^{1-3}$ Moira Strand Hutchinson, ${ }^{1,3}$ \\ Marie Kjærgaard, ${ }^{1,2}$ Lone Jørgensen, ${ }^{1,7}$ and Guri Grimnes ${ }^{1-3}$
}

Objective: High serum thyrotropin (TSH) levels predict cardiovascular disease (CVD). Recently several single nucleotide polymorphisms (SNPs) associated with TSH levels have been identified, one of them being the rs4704397 SNP in the phosphodiesterase 8B (PDE8B) gene. If the relation between thyroid function and CVD is causal, one could also expect rs4704397 genotypes to predict CVD and possibly health in general.

Methods: DNA was prepared and genotyping performed for rs4704397 in subjects who participated in the fourth survey of the Tromsø Study in 1994-1995 and who were registered with the endpoints myocardial infarction (MI), type 2 diabetes (T2DM), cancer, or death, as well as a randomly selected control group. Similarly, genotyping was performed in subjects who had participated in clinical trials where serum TSH, free T4 (fT4), and free T3 (fT3) were measured.

Results: From the Tromsø Study, 8938 subjects without thyroid disease or thyroid medication were successfully genotyped for rs4704397. Among these, 2098 were registered with MI, 1025 with T2DM, 2748 with cancer, and 3592 had died. The minor homozygote genotype (A:A) had a median serum TSH level that was $0.29 \mathrm{mIU} / \mathrm{L}$ higher than in the major homozygote genotype (G:G). The A:A genotype had a significantly increased risk of MI as compared to the G:G genotype (1.14 [1.00-1.29], hazard ratio [confidence interval], Cox regression with adjustment for age, sex, and body mass index). No significant associations were seen with the other endpoints or CVD risk factors. Furthermore, subjects with the G:G genotype were significantly taller than subjects with the A:A genotype (mean difference $1.5 \mathrm{~cm}$ ). In 584 subjects with serum TSH, fT4, and fT3 measurements, the subjects with the A:A genotype had significantly higher serum TSH and nonsignificantly lower serum fT3 (mean difference $0.15 \mathrm{pmol} / \mathrm{L}$ ) levels than subjects with the G:G genotype.

Conclusion: rs4704397 is associated with thyroid function, risk of MI, and body height. However, confirmation in other cohorts is needed before firm conclusions can be drawn.

\section{Introduction}

$\mathbf{T}$ HE THYROID HORMONES THYROXINE (T4) and triiodothyronine (T3) are essential for normal metabolic function and control a wide range of physiological processes. The secretion of T4 and T3 is regulated by thyrotropin (TSH) from the pituitary and controlled by a negative-feedback loop. In primary thyroid disease, high serum TSH levels indicate hypofunction of the thyroid gland, whereas low levels reflect hyperfunction. The serum TSH level is therefore a sensitive indicator of thyroid status (1).

It is well known that overt as well as subclinical hypothyroidism are associated with cardiovascular disease (CVD) and increased mortality $(2,3)$, and it has also been demonstrated that TSH levels, even within the reference range, predict fatal coronary heart disease (4). In previous studies, we and others

\footnotetext{
${ }^{1}$ Tromsø Endocrine Research Group, and ${ }^{5}$ Brain and Circulation Research Group, ${ }^{3}$ Department of Clinical Medicine; ${ }^{4}$ Department of Community Medicine; ${ }^{6}$ Department of Medical Biology, Faculty of Health Sciences; and ${ }^{7}$ Department of Health and Care Sciences; University of Troms $\varnothing$, Tromsø, Norway.

${ }^{2}$ Division of Internal Medicine, University Hospital of North Norway, Tromsø, Norway.
} 
have found an association between serum TSH within the reference range and serum lipid levels $(5,6)$, body weight $(7,8)$, and blood pressure (9). Altered serum TSH level appears to be an important risk factor for disease in general.

Whether there is a causal relation between moderately elevated serum TSH and future disease is uncertain and can best be answered by properly performed randomized controlled trials (RCTs). Such RCTs would, however, need to include a large number of subjects followed for a long period of time, and so it is unlikely to ever be performed. However, nature has, in a way, already performed its own "RCT" just waiting to be analyzed. Thus, the free thyroxine (fT4), free triiodothyroinine (fT3), and TSH levels are, in part, genetically determined, as demonstrated in several genome wide association studies (GWAS) where single nucleotide polymorphisms (SNPs) related to thyroid function have been identified (10-12). In particular, the rs4704397 SNP in the phosphodiesterase $8 \mathrm{~B}$ (PDE8B) gene appears to be one of the SNPs most strongly associated with the serum TSH level (13$15)$, and one copy of the rare A allele confers a mean increase of $0.13 \mathrm{mIU} / \mathrm{L}$ TSH (13) resulting in a difference between the major and minor homozygote subjects of $\sim 0.25 \mathrm{mIU} / \mathrm{L} \mathrm{TSH}$. This SNP has been associated with subclinical hypothyroidism (15), but to our knowledge has not been evaluated with regard to CVD and other diseases.

In the fourth survey in the Tromsø Study performed in 1994-1995, blood samples for preparation of DNA were collected and analyzed in more than 9000 subjects. The participants have been monitored with registration of incident myocardial infarction (MI), type 2 diabetes (T2DM), cancer, and death, and we therefore had the opportunity to test if this SNP is related to hard endpoints as well as CVD risk factors. Furthermore, we analyzed fT4 and fT3 measurements from a large cohort of subjects also genotyped for rs4704397, and the effect on this SNP on these thyroid hormones could also be evaluated.

\section{Methods}

\section{The Tromsø Study}

The design of the Tromsø Study has been described in detail by Jacobsen et al. (16). In short, the Tromsø Study is a longitudinal population-based multipurpose study focusing on lifestyle-related diseases. The study was initiated in 1974, and has been repeated six times at regular intervals. The participants are inhabitants of the municipality of Tromsø in Northern Norway situated at $69^{\circ} \mathrm{N}$ with a current population of 70,000 inhabitants. In the fourth survey in 1994-1995 ("1994" hereafter), all individuals aged 25 years or older were invited and 2758 subjects participated, providing an attendance rate of $77 \%$.

\section{Measurements in 1994}

The participants completed questionnaires on medical history including thyroid diseases and thyroid medication. Blood pressure, height, and weight were measured as previously described in all subjects, and waist and hip circumference was determined in a subgroup (9). Nonfasting blood samples were analyzed consecutively for serum total cholesterol, triglycerides, and high-density lipoprotein cholesterol (HDL-cholesterol) in all subjects (5), and serum TSH (9) and
$\mathrm{HbA}_{1 \mathrm{c}}$ (17) were determined in subgroups. DNA was prepared from blood clots stored at the national CONOR (Cohort of Norway) bio-bank, located at the HUNT/NTNU biobank in Levanger (18). The SNP rs4704397 was selected due to the reported strong association with serum TSH levels (13-15). The genotyping was performed by LGC Genomics (formerly KBioscience, Hoddesdon, United Kingdom) using the KBioscience Competitive Allele-Specific PCR genotyping system (18).

\section{Selection of subjects for genetic studies}

The selection of subjects for the genetic studies has been described in detail previously (18). In short, the subjects were primarily selected for evaluation of genetic polymorphisms and hard endpoints for which there are several registers in the Tromsø Study. Information on cancer and death are available from national registries. As all of these endpoints were of potential interest regarding genetic polymorphisms, and limited funding did not allow genetic analyses of the entire Tromsø Study cohort, a case-cohort design was used with randomly selected controls from the entire cohort who attended the fourth survey in 1994 (19). The selection of the controls was unrelated to the characteristics of the cases except for age. Accordingly, genotyping was performed in all subjects included in the endpoint registers as well as the randomly selected controls.

\section{Definition of endpoints}

The definitions of incident MI and T2DM have previously been described in detail $(18,20,21)$. Information on cancer incidence and cancer location was retrieved from the Cancer Registry of Norway. Information on death was obtained from the Causes of Death Registry, and information on moving out of the Tromsø area and emigration from Norway was obtained from the Norwegian Registry of Vital Statistics.

\section{Study on subjects with TSH, fT4, and fT3 measurements}

In the present study, we pooled baseline data from a vitamin D and bone-density study including 297 postmenopausal women aged 50-80 years with a T-score in total hip or lumbar spine (L2-4) $\leq-2.0$ (22), and a vitamin D and depression study comprising 357 subjects aged 30-75 years (23). Serum TSH, fT4, and fT3 were measured as previously described (9).

\section{Statistical analyses}

Distribution of the continuous variables was evaluated for skewness and kurtosis and with visual inspection of histograms, and was found to be normal except for $\mathrm{HbA}_{1 \mathrm{c}}$ and serum TSH, which were normalized by $\log$ transformation before use as dependent variables. Trends across the SNP rs4704397 genotypes were evaluated with linear regression analyses with age, sex, and body mass index (BMI) as covariates, where appropriate.

The relations between the rs4704397 genotypes with the endpoints MI, T2DM, cancer, and all-cause mortality were evaluated using Cox proportional hazard regression model with age, sex, and BMI as covariates. The observation time for mortality was set from the survey in 1994 and for the other endpoints from birth. These latter endpoint groups therefore 
included both prevalent and incident cases. The endpoints registers were updated throughout 2008 for T2DM and cancer, and throughout 2010 for MI and mortality.

The predefined control cohort was used as controls for the subjects with a specific endpoint (cases). Since this control cohort was randomly selected from the entire cohort, it also included a considerable number of subjects with one or more endpoints. When analyzing a specific endpoint, subjects in the control cohort with that specific endpoint were moved to the case group (which only included subjects with that specific endpoint). Therefore, the size of the control cohort varied depending on the endpoint in question.

The genotype frequency was evaluated for HardyWeinberg equilibrium with chi-square analysis (24). For the Troms $\varnothing$ Study cohort, the chi-square value was $6.43(p<0.05)$; in the control cohort, it was $4.24(p<0.05)$, whereas in the cohort with subjects with TSH, fT4, and fT3 measurements, the chi-square value was $3.42\left(p>0.05 ; \chi^{2}=3.84\right.$ with one degree of freedom corresponds to a two-tailed probability of 0.05).

Baseline characteristics are presented as mean (SD), median (25th-75th percentiles), or percentage. All tests were twosided, and a $p$-value of $<0.05$ was considered statistically significant.

\section{Ethics}

The study was approved by the Regional Committee for Medical and Health Research Ethics (REK Nord, reference 2010/2913-4). Only participants with valid written consent were included. The studies were registered at ClinicalTrials.gov (NCT01395303, NTC00491920, and NCT00960232).

\section{Results}

\section{The Tromsø Study}

Cross-sectional part. A total of 9528 subjects were selected for participation in the study, and DNA was successfully prepared and analyzed for rs4704397 in 9388 subjects. Among these, 450 subjects reported use of medication for thyroid disease and/or previous or current thyroid disease, leaving 8938 subjects for the present study. Their baseline characteristics in relation to rs4704397 genotype are shown in Table 1. There was a significant increase in body height, body weight, and waist and hip circumferences across the genotypes, with the major homozygote $(\mathrm{G}: \mathrm{G})$ having the highest values. Thus, subjects with the G:G genotype had a mean body height $1.5 \mathrm{~cm}$ above the A:A genotype subjects. However, there was no significant relation to BMI or waist-hip ratio. There was a significant trend for serum TSH across the genotypes, with the minor homozygote (A:A) genotype having a median serum TSH $0.29 \mathrm{mIU} / \mathrm{L}$ higher than the major homozygote genotype (G:G). No significant effects on blood pressure or serum lipids were observed. The relation between body height and rs4704397 genotype was seen in both sexes and all age groups (Table 2).

Relation between rs4704397 genotypes and endpoints. The total number of potential controls was 3932, and 2098, 1025, 2748, and 3592 subjects were registered with MI, T2DM, cancer, or death respectively. Their characteristics in 1994 are shown in Table 3. In Table 4, hazard ratios for the endpoints according to genotype are presented with the major homozygote as reference. The minor homozygote genotype A:A, which was the one associated with the highest serum

Table 1. Baseline Characteristics of the 8938 Subjects in 1994 in Relation to Rs4704397 Genotype: The Tromsø Study

\begin{tabular}{|c|c|c|c|}
\hline & \multicolumn{3}{|c|}{ rs4704397 (PDE8B) } \\
\hline & $A: A$ & $A: G$ & $G: G$ \\
\hline \multicolumn{4}{|c|}{ All subjects in the fourth survey of the Tromsø Study } \\
\hline$N$ & 1399 & 4129 & 3410 \\
\hline Males (\%) & 46.7 & 48.5 & 50.2 \\
\hline Age (years) & $59.8(13.6)$ & $59.2(13.7)$ & $59.5(13.8)$ \\
\hline Smokers $(\%)$ & 35.4 & 35.1 & 33.9 \\
\hline Systolic blood pressure (mmHg) & $144.4(24.1)$ & $145.0(24.0)$ & $145.0(23.5)$ \\
\hline Diastolic blood pressure (mmHg) & $82.5(13.1)$ & $83.1(13.6)$ & $83.1(13.4)$ \\
\hline Body height $(\mathrm{cm})$ & $167.1(9.7)$ & $168.1(9.8)$ & $168.6(9.6)^{* * *}$ \\
\hline Body weight $(\mathrm{kg})$ & $72.6(14.0)$ & $73.5(14.2)$ & $74.1(14.2)^{* *}$ \\
\hline $\mathrm{BMI}\left(\mathrm{kg} / \mathrm{m}^{2}\right)$ & $25.9(4.0)$ & $25.9(4.1)$ & $26.0(4.2)$ \\
\hline Serum total cholesterol (mmol/L) & $6.65(1.31)$ & $6.56(1.31)$ & $6.59(1.39)$ \\
\hline Serum triglycerides $(\mathrm{mmol} / \mathrm{L})$ & $1.73(1.19)$ & $1.69(1.06)$ & $1.69(1.10)$ \\
\hline Serum HDL-cholesterol (mmol/L) & $1.52(0.44)$ & $1.52(0.43)$ & $1.51(0.43)$ \\
\hline Subjects with TSH measurements (n) & 348 & 976 & 813 \\
\hline Serum TSH $(\mathrm{mIU} / \mathrm{L})$ & $1.74(1.23,2.65)$ & $1.64(1.16,2.34)$ & $1.45(1.03,2.12)^{* * *}$ \\
\hline Subjects with $\mathrm{Hb} A_{1 c}$ measurements (n) & 710 & 1964 & 1646 \\
\hline $\mathrm{HbA}_{1 \mathrm{c}}(\%)$ & $5.45(5.2,5.7)$ & $5.4(5.2,5.7)$ & $5.4(5.2,5.7)$ \\
\hline Subjects with waist and hip measurements (n) & 702 & 1963 & 1651 \\
\hline Waist $(\mathrm{cm})$ & $90.4(11.5)$ & $91.1(11.5)$ & $91.8(11.6)^{*}$ \\
\hline Hip $(\mathrm{cm})$ & $103.1(7.9)$ & $103.5(8.1)$ & $103.9(7.9)^{*}$ \\
\hline Waist-hip ratio & $0.88(0.09)$ & $0.88(0.08)$ & $0.88(0.08)$ \\
\hline
\end{tabular}

${ }^{*} p<0.05 ;{ }^{* *} p<0.01 ;{ }^{* * *} p<0.001$; test of linear trend adjusted for age, BMI (where appropriate) and gender. Data are shown as mean (SD), median (25th-75th percentiles), or percentage. 
Table 2. Body Height in 1994 in Relation to Gender, Age, and rs4704397 Genotype: The Tromsø Study

\begin{tabular}{|c|c|c|c|c|c|c|}
\hline & \multicolumn{6}{|c|}{ rs4704397 (PDE8B) } \\
\hline & \multicolumn{2}{|c|}{$A: A$} & \multicolumn{2}{|c|}{$A: G$} & \multicolumn{2}{|c|}{$G: G$} \\
\hline & $\mathrm{n}$ & Height $(\mathrm{cm})$ & $\mathrm{n}$ & Height $(\mathrm{cm})$ & $\mathrm{n}$ & Height $(\mathrm{cm})$ \\
\hline \multicolumn{7}{|l|}{ Males } \\
\hline All males & 653 & $174.5(7.0)$ & 2002 & $175.2(7.2)$ & 1711 & $175.6(6.9)^{* *}$ \\
\hline Age $<50$ years & 161 & $176.9(6.7)$ & 520 & $177.5(7.2)$ & 447 & $178.3(6.7)^{*}$ \\
\hline Age 50-69 years & 346 & $174.6(6.8)$ & 1041 & $175.1(7.0)$ & 860 & $175.7(6.3)^{* *}$ \\
\hline Age $>69$ years & 146 & $171.7(6.9)$ & 441 & $172.6(6.6)$ & 404 & $172.4(7.1)$ \\
\hline \multicolumn{7}{|l|}{ Females } \\
\hline All females & 746 & $160.7(6.7)$ & 2127 & $161.5(6.9)$ & 1699 & $161.6(6.3)^{*}$ \\
\hline Age <50 years & 176 & $163.5(6.5)$ & 556 & $165.4(6.5)$ & 417 & $165.4(5.6)^{* *}$ \\
\hline Age 50-69 years & 359 & $161.4(6.0)$ & 962 & $161.6(6.2)$ & 784 & $161.7(5.7)$ \\
\hline Age > 69 years & 211 & $157.0(6.5)$ & 609 & $157.7(6.3)$ & 498 & $158.4(6.0)^{* *}$ \\
\hline
\end{tabular}

${ }^{*} p<0.05 ;{ }^{* *} p<0.01$; test of linear trend.

TSH levels, had a significant $14 \%$ increased risk for MI. For the other endpoints, no significant relations to rs4704397 genotypes were seen.

Study on subjects with TSH, fT4, and fT3 measurements. A total of 289 subjects in the osteoporosis study and 341 subjects in the depression study had complete data sets. Among these subjects, 46 were using thyroid medication or had thyroid disease and were therefore excluded, thus leaving 584 for the present analysis. The pooled characteristics in relation to rs4704397 genotypes are shown in Table 5. There was a significant linear trend across the rs4704397 genotypes for serum TSH with the minor homozygote A:A having the highest serum TSH levels. There was a trend for a reciprocal association with fT3, with the genotype A:A having the lowest level. However, this was not statistically significant after inclusion of BMI in the analysis.

\section{Discussion}

In the present study, we have confirmed the relation between rs4704397 genotypes and serum TSH, and also demonstrated a possible relation to fT3. Furthermore, there was a significant relation between rs4704397 genotypes and body height and risk of MI, but not for the other endpoints-T2DM, cancer, or mortality.

Table 3. Baseline Characteristics in 1994 of the Subjects in the Control Group, and Subjects with MI, T2DM, Cancer, and Death: The Tromsø Study

\begin{tabular}{|c|c|c|c|c|c|}
\hline & Control group & MI & $T 2 D M$ & Cancer & Death \\
\hline$N$ & 3932 & 2098 & 1025 & 2748 & 3592 \\
\hline Males (\%) & 44.5 & 65.7 & 53.7 & 49.9 & 53.5 \\
\hline Age (years) & $65.5(12.6)$ & $64.2(12.0)$ & $59.9(12.5)$ & $58.9(13.8)$ & $67.1(12.7)$ \\
\hline Smokers (\%) & 27.6 & 36.0 & 29.5 & 36.7 & 35.7 \\
\hline $\begin{array}{l}\text { Systolic blood pressure } \\
(\mathrm{mmHg})\end{array}$ & $149.0(24.7)$ & $151.1(24.1)$ & $151.7(23.3)$ & $142.8(23.3)$ & $152.2(25.4)$ \\
\hline $\begin{array}{l}\text { Diastolic blood pressure } \\
(\mathrm{mmHg})\end{array}$ & $83.8(13.8)$ & $86.0(13.8)$ & $86.3(13.7)$ & $81.9(13.1)$ & $85.2(14.5)$ \\
\hline BMI $\left(\mathrm{kg} / \mathrm{m}^{2}\right)$ & $25.9(4.1)$ & $26.6(4.0)$ & $29.0(4.8)$ & $25.7(4.0)$ & $25.9(4.3)$ \\
\hline $\begin{array}{l}\text { Serum total cholesterol } \\
(\mathrm{mmol} / \mathrm{L})\end{array}$ & $6.69(1.33)$ & $6.93(1.28)$ & $6.69(1.22)$ & $6.41(1.31)$ & $6.69(1.34)$ \\
\hline $\begin{array}{l}\text { Serum triglycerides } \\
(\mathrm{mmol} / \mathrm{L})\end{array}$ & $1,68(1.07)$ & $1.98(1.22)$ & $2.40(1.57)$ & $1.61(1.01)$ & $1.75(1.09)$ \\
\hline $\begin{array}{l}\text { Serum HDL-cholesterol } \\
\quad(\mathrm{mmol} / \mathrm{L})\end{array}$ & $1.54(0.44)$ & $1.39(0.40)$ & $1.32(0.38)$ & $1.52(0.42)$ & $1.51(0.44)$ \\
\hline $\begin{array}{l}\text { Subjects with TSH } \\
\text { measurements (n) }\end{array}$ & 1005 & 557 & 278 & 642 & 847 \\
\hline Serum TSH (mIU/L) & $1.61(1.14,2.34)$ & $1.53(1.10,2.28)$ & $1.59(1.17,2.16)$ & $1.61(1.13,2.23)$ & $1.58(1.07,2.25)$ \\
\hline $\begin{array}{l}\text { Subjects with } \mathrm{Hb} A_{1 c} \\
\text { measurements }(\mathrm{n})\end{array}$ & 1967 & 1096 & 527 & 1319 & 1662 \\
\hline $\mathrm{HbA}_{1 \mathrm{c}}(\%)$ & $5.4(5.2,5.7)$ & $5.5(5.2,5.8)$ & $5.9(5.6,6.6)$ & $5.4(5.2,5.7)$ & $5.5(5.2,5.7)$ \\
\hline $\begin{array}{l}\text { Subjects with waist/hip } \\
\text { measurements (n) }\end{array}$ & 2027 & 1153 & 543 & 1291 & 1739 \\
\hline Waist-hip ratio & $0.87(0.81,0.93)$ & $0.91(0.85,0.96)$ & $0.92(0.86,0.97)$ & $0.88(0.82,0.93)$ & $0.89(0.83,0.95)$ \\
\hline
\end{tabular}

Data are shown as mean (SD), median (25th-75th percentiles), or percentage. 
Table 4. Number of Subjects with Specific Endpoints and Number of Subjects in Corresponding Control Groups and Hazard Ratio with Confidence Interval in Relation to Genotype: The Tromsø Study

\begin{tabular}{lcccc}
\hline & MI & T2DM & Cancer & Death \\
\hline Endpoint $(n)$ & 2098 & 1025 & 2748 & 3592 \\
Controls $(n)$ & 3078 & 3600 & 3075 & 2244 \\
rs4704397 & & & & \\
$\quad$ Major homozygote (G:G) & Reference & Reference & Reference & Reference \\
$\quad$ Heterozygote (G:A) & $1.07(0.97-1.17)$ & $1.06(0.92-1.21)$ & $1.02(0.94-1.11)$ & $1.00(0.93-1.08)$ \\
$\quad$ Minor homozygote (A:A) & $1.14(1.00-1.29)^{*}$ & $1.02(0.85-1.24)$ & $1.10(0.98-1.23)$ & $1.07(0.97-1.18)$ \\
\hline
\end{tabular}

${ }^{*} p<0.05$; Cox regression with adjustment for age, gender, and BMI.

The relation between rs4704397 and serum TSH has been reported before. Arnaud-Lopez et al. genotyped 362,129 SNPs in 4300 subjects and found a strong relation between rs4704397 and serum TSH, a finding that was replicated in another 4158 subjects (13). Each copy of the minor allele was associated with an increase of $0.13 \mu \mathrm{IU} / \mathrm{mL}$ in serum TSH, which is comparable to what we found in our two cohorts. This was confirmed in a study by Shields et al. in 877 pregnant women (15), and also in a meta-analysis by Taylor et al. who, in addition to the relation with serum TSH, also found a reciprocal association with $\mathrm{fT} 4$, indicating relative hypothyroidism (14). In our study, we found a corresponding reciprocal association with $\mathrm{fT} 3$, which could indicate relative hypothyroidism. However, the association was weak and not significant after inclusion of BMI in the analysis. Similarly, in the two large studies by Gudmundsson et al. (11) and by Porcu et al. (12), this reciprocal relation was not statistically significant.

The mechanism for this effect, if present, is most likely due to the function of the PDE8B gene, where the SNP rs4704397 is located, as it encodes a high-affinity cAMP-specific phosphodiesterase (25). The PDE8B gene is not expressed in the pituitary (26) but in the thyroid where it is supposed to catalyze inactivation of cAMP after TSH stimulation (13). Thus, as thyroid hormone secretion is stimulated by TSH via a cAMP-dependent pathway (27), the PDE8B gene could influence the TSH level by affecting the T4 and T3 secretion by the thyroid (13).

Thyroid function affects longitudinal bone growth, and hypothyroidism is associated with retarded growth (28). For subclinical hypothyroidism, there are only a few studies in children/adolescents, and it appears that thyroxine treatment leads to increased growth (29). Our finding of a relation between rs4704397 SNP and body height is therefore plausible. It would have been of great interest to see if this relation also applied to children and adolescents, but unfortunately we did not have any subjects younger than 25 years of age. The mean difference in height between the major and minor homozygote genotypes for the rs 4704397 SNP was $1.5 \mathrm{~cm}$. This is a considerable height difference, as according to most analyses, the effect size of SNPs associated with height ranges from 0.2 to $0.5 \mathrm{~cm}$ per allele (30). More than 200 polymorphisms associated with adult height have been identified (30,31). Even when all these SNPs are taken together, they can only explain $45 \%$ of the genetic variance in height (32). It is probable that a number of SNPs have not been "detected" by GWAS, since SNPs with minor effects will not pass the stringent significance tests in these studies. In our study, we used a different approach and only included one SNP based on the known relation to serum TSH and thereby avoided the need for correcting for testing a multitude of SNPs.

In addition to elucidating factors that determine adult height, our finding may shed light on other diseases. In this regard, it is noteworthy that body height has been associated with several cancers (33), CVD (34), as well as mortality (35). However, the most remarkable finding in our study was the relation between rs4704397 and the risk of MI. It is well known that overt hypothyroidism is associated with atherosclerosis and heart disease (2), which also seems to be the case for subclinical hypothyroidism. Thus, in the meta-analysis by

Table 5. Characteristics of the 584 Subjects with Serum TSH, fT4 and FT3 Measurements in Relation to RS4704397 Genotype

\begin{tabular}{|c|c|c|c|}
\hline & \multicolumn{3}{|c|}{ rs4704397 (PDE8B) } \\
\hline & $A: A$ & $A: G$ & $G: G$ \\
\hline All 584 subjects $(n)$ & 101 & 250 & 233 \\
\hline Osteoporosis study (females only, $n$ ) & 46 & 118 & 94 \\
\hline Depression study $(n)$ & 55 & 132 & 139 \\
\hline Percentage males in depression study & 38.2 & 46.2 & 51.1 \\
\hline \multicolumn{4}{|l|}{ All 584 subjects } \\
\hline Age (years) & $56.5(11.6)$ & $57.2(10.0)$ & $56.9(10.2)$ \\
\hline BMI $\left(\mathrm{kg} / \mathrm{m}^{2}\right)$ & $26.4(4.2)$ & $26.2(4.0)$ & $26.3(3.8)$ \\
\hline Serum TSH $(\mathrm{mIU} / \mathrm{L})^{*}$ & $1.89(1.30,2.46)$ & $1.58(1.17,2.24)$ & $1.63(1.12,2.13) * *$ \\
\hline Serum FT4 (nmol/L) & $15.7(2.1)$ & $15.9(2.0)$ & $16.1(2.2)$ \\
\hline Serum FT3 (pmol/L) & $4.57(0.56)$ & $4.63(0.62)$ & $4.72(0.60)$ \\
\hline
\end{tabular}

${ }^{*}$ Log transformed in the linear regression. ${ }^{* *} p<0.05$; test of linear trend adjusted for age, BMI, and gender. Data are shown as mean (SD), median (25th-75th percentiles), or percentage. 
Rodondi et al., subclinical hypothyroidism (defined as elevated serum TSH with normal fT4) was associated with increased risk of coronary heart disease (3). Of note was that the results were similar after further adjustment for traditional cardiovascular risk factors like blood pressure and cholesterol, and that they did not differ by age or sex. The relation between TSH and coronary disease has even been demonstrated within the serum TSH reference range in the HUNT study, a large population-based cohort study from Norway (4). The study included 17,311 women and 8002 men without known thyroid or cardiovascular disease or diabetes mellitus at baseline followed up for a median of 8.3 years. Among the subjects with TSH within the reference range at baseline $(0.50$ $3.5 \mathrm{mIU} / \mathrm{L}$ ), the TSH levels were positively associated with mortality from coronary heart disease, the trend being statistically significant in women but not in men (4). This finding was later confirmed from the same group after a median follow-up time of 12.3 years (36).

Accordingly, small changes in TSH may have considerable effects on CVD. However, cross-sectional or prospective studies cannot answer the question of causality, for which RCTs are needed. A surrogate for RCT is to use the Mendelian randomization approach (37) where the cohort at birth (or conception) is considered "randomized" to a certain genotype. In the case of rs4704397, individuals "randomized" to the minor homozygote genotype will presumably have higher TSH levels and possibly also lower fT3 levels throughout life than the individuals "randomized" to the major homozygote genotype. Accordingly, this difference in thyroid function, although small, will be present throughout life and may therefore be a stronger predictor of health than a single TSH measurement, as is usually the case in prospective studies. Our finding of a relation between rs4704397 and the risk of MI is therefore not unexpected. Similar to that seen for subclinical hypothyroidism, the relation can hardly be explained by association with the classical risk factors for atherosclerosis such as blood pressure and hyperlipidemia, as there was no association with these risk factors and rs4704397. Furthermore, it was not related to BMI, which was included in the analyses because an interaction between adiposity and the PDE8B gene on serum TSH has been described (38). On the other hand, it could possibly be related to other factors like increased systemic vascular resistance, arterial stiffness, altered endothelial function, and coagulability, which have all been reported to be associated with subclinical hypothyroidism and which may accelerate development of coronary heart disease (39).

Although the result from the Mendelian randomization was significant, this is still not proof of a causal relation. Thus, the rs4704397 SNP could very well be associated with other genes that were the ones truly causing the observed effect, and therefore rs4704397 may only be a marker of disease risk. Furthermore, the Tromsø Study population was not in HardyWeinberg equilibrium regarding rs4704397, and the results may therefore have been biased. This could possibly be explained by the high proportion of Sami ancestry in the Tromsø population (40), as this group could have a different allele frequency than the majority of the Tromsø population, which is a non-Sami Caucasian population. Unfortunately, we did not have any ancestry-informative SNPs that could verify this hypothesis. However, in the control group, the deviation from the Hardy-Weinberg equilibrium was small, and the results can therefore most likely be considered reliable.
In conclusion, we have found rs4704397 to be associated with the serum TSH and fT3 levels with a corresponding increased risk of MI. This is an argument for, but no proof of, a causal relation between increased TSH levels and cardiovascular risk. Furthermore, as is the case with all genetic studies of this type, confirmation in other cohorts is needed.

\section{Acknowledgments}

We are indebted to the National Health Screening Service for their participation in collection of data in the fourth Tromsø Study. The superb assistance by the nurses at the Clinical Research Unit at the University Hospital of North Norway is gratefully acknowledged. The present study was supported by grants from The North Norway Regional Health Authority, The University of Tromsø, The Research Council of Norway, The Norwegian Women Public Health Association in Troms, and the Norwegian Council of Cardiovascular Disease.

\section{Author Disclosure Statement}

The authors declare that no competing financial interests exist.

\section{References}

1. Yen PM 2001 Physiological and molecular basis of thyroid hormone action. Physiol Rev 81:1097-1142.

2. Becker C 1985 Hypothyroidism and atherosclerotic heart disease: pathogenesis, medical management, and the role of coronary artery bypass surgery. Endocr Rev 6:432-440.

3. Rodondi N, den Elzen WP, Bauer DC, Cappola AR, Razvi S, Walsh JP, Asvold BO, Iervasi G, Imaizumi M, Collet TH, Bremner A, Maisonneuve P, Sgarbi JA, Khaw KT, Vanderpump MP, Newman AB, Cornuz J, Franklyn JA, Westendorp RG, Vittinghoff E, Gussekloo J 2010 Thyroid Studies Collaboration. Subclinical hypothyroidism and the risk of coronary heart disease and mortality. JAMA 304:1365-1374.

4. Asvold BO, Bjøro T, Nilsen TI, Gunnell D, Vatten LJ 2008 Thyrotropin levels and risk of fatal coronary heart disease: the HUNT study. Arch Intern Med 168:8558-8560.

5. Iqbal A, Jorde R, Figenschau Y 2006 Serum lipid levels in relation to serum thyroid-stimulating hormone and the effect of thyroxine treatment on serum lipid levels in subjects with subclinical hypothyroidism: the Tromsø Study. J Intern Med 260:53-61.

6. Asvold BO, Vatten LJ, Nilsen TI, Bjøro T 2007 The association between TSH within the reference range and serum lipid concentrations in a population-based study. The HUNT Study. Eur J Endocrinol 156:181-186.

7. Nyrnes A, Jorde R, Sundsfjord J 2006 Serum TSH is positively associated with BMI. Int J Obes 30:100-105.

8. Svare A, Nilsen TI, Bjøro T, Asvold BO, Langhammer A 2011 Serum TSH related to measures of body mass: longitudinal data from the HUNT Study, Norway. Clin Endocrinol 74:769-775.

9. Iqbal A, Figenschau Y, Jorde R 2006 Blood pressure in relation to serum thyrotropin: the Tromsø Study. J Hum Hypertens 20:932-936.

10. Rawal R, Teumer A, Völzke $H$, Wallaschofski $H$, Ittermann $\mathrm{T}$, Åsvold BO, Bjøro T, Greiser KH, Tiller D, Werdan K, zu Schwabedissen HE, Doering A, Illig T, Gieger C, Meisinger C, Homuth G 2012 Meta-analysis of two genome-wide association studies identifies four genetic loci associated with thyroid function. Hum Mol Genet 21:3275-3282. 
11. Gudmundsson J, Sulem P, Gudbjartsson DF, Jonasson JG, Masson G, He H, Jonasdottir A, Sigurdsson A, Stacey SN, Johannsdottir H, Helgadottir HT, Li W, Nagy R, Ringel MD, Kloos RT, de Visser MC, Plantinga TS, den Heijer M, Aguillo E, Panadero A, Prats E, Garcia-Castaño A, De Juan A, Rivera F, Walters GB, Bjarnason H, Tryggvadottir L, Eyjolfsson GI, Bjornsdottir US, Holm H, Olafsson I, Kristjansson K, Kristvinsson $\mathrm{H}$, Magnusson OT, Thorleifsson G, Gulcher JR, Kong A, Kiemeney LA, Jonsson T, Hjartarson H, Mayordomo JI, Netea-Maier RT, de la Chapelle A, Hrafnkelsson J, Thorsteinsdottir U, Rafnar T, Stefansson K 2012 Discovery of common variants associated with low TSH levels and thyroid cancer risk. Nat Genet 44:319-322.

12. Porcu E, Medici M, Pistis G, Volpato CB, Wilson SG, Cappola AR, Bos SD, Deelen J, den Heijer M, Freathy RM, Lahti J, Liu C, Lopez LM, Nolte IM, O'Connell JR, Tanaka T, Trompet S, Arnold A, Bandinelli S, Beekman M, Böhringer S, Brown SJ, Buckley BM, Camaschella C, de Craen AJ, Davies G, de Visser MC, Ford I, Forsen T, Frayling TM, Fugazzola L, Gögele M, Hattersley AT, Hermus AR, Hofman A, Houwing-Duistermaat JJ, Jensen RA, Kajantie E, Kloppenburg M, Lim EM, Masciullo C, Mariotti S, Minelli C, Mitchell BD, Nagaraja R, Netea-Maier RT, Palotie A, Persani L, Piras MG, Psaty BM, Räikkönen K, Richards JB, Rivadeneira F, Sala C, Sabra MM, Sattar N, Shields BM, Soranzo N, Starr JM, Stott DJ, Sweep FC, Usala G, van der Klauw MM, van Heemst D, van Mullem A, Vermeulen SH, Visser WE, Walsh JP, Westendorp RG, Widen E, Zhai G, Cucca F, Deary IJ, Eriksson JG, Ferrucci L, Fox CS, Jukema JW, Kiemeney LA, Pramstaller PP, Schlessinger D, Shuldiner AR, Slagboom EP, Uitterlinden AG, Vaidya B, Visser TJ, Wolffenbuttel BH, Meulenbelt I, Rotter JI, Spector TD, Hicks AA, Toniolo D, Sanna S, Peeters RP, Naitza S 2013 A meta-analysis of thyroid-related traits reveals novel Loci and gender-specific differences in the regulation of thyroid function. PLoS Genet 9:e1003266.

13. Arnaud-Lopez L, Usala G, Ceresini G, Mitchell BD, Pilia MG, Piras MG, Sestu N, Maschio A, Busonero F, Albai G, Dei M, Lai S, Mulas A, Crisponi L, Tanaka T, Bandinelli S, Guralnik JM, Loi A, Balaci L, Sole G, Prinzis A, Mariotti S, Shuldiner AR, Cao A, Schlessinger D, Uda M, Abecasis GR, Nagaraja R, Sanna S, Naitza S 2008 Phosphodiesterase 8B gene variants are associated with serum TSH levels and thyroid function. Am J Hum Genet 82:1270-1280.

14. Taylor PN, Panicker V, Sayers A, Shields B, Iqbal A, Bremner AP, Beilby JP, Leedman PJ, Hattersley AT, Vaidya B, Frayling T, Evans J, Tobias JH, Timpson NJ, Walsh JP, Dayan CM 2011 A meta-analysis of the associations between common variation in the PDE8B gene and thyroid hormone parameters, including assessment of longitudinal stability of associations over time and effect of thyroid hormone replacement. Eur J Endocrinol 164:773-780.

15. Shields BM, Freathy RM, Knight BA, Hill A, Weedon MN, Frayling TM, Hattersley AT, Vaidya B 2009 Phosphodiesterase $8 \mathrm{~B}$ gene polymorphism is associated with subclinical hypothyroidism in pregnancy. J Clin Endocrinol Metab 94:4608-4612.

16. Jacobsen BK, Eggen AE, Mathiesen EB, Wilsgaard T, Njølstad I 2012 Cohort profile: the Tromso Study. Int J Epidemiol 41:961-967.

17. Grimnes G, Emaus N, Joakimsen RM, Figenschau Y, Figenschau Y, Jenssen T, Njølstad I, Schirmer H, Jorde R 2010 Baseline serum 25-hydroxyvitamin $\mathrm{D}$ concentrations in the Tromsø Study 1994-95 and risk of developing type 2 dia- betes mellitus during 11 years of follow-up. Diabet Med 27:1107-1115.

18. Jorde R, Schirmer H, Wilsgaard T, Joakimsen RM, Mathiesen EB, Njølstad I, Løchen ML, Figenschau Y, Berg JP, Svartberg J, Grimnes G 2012 Polymorphisms related to the serum 25hydroxyvitamin D level and risk of myocardial infarction, diabetes, cancer and mortality. The Tromsø Study. PLoS One 7:e37295.

19. Kulathinal S, Karvanen J, Saarela O, Kuulasmaa K 2007 Case-cohort design in practice-experiences from the MORGAM Project. Epidemiol Perspect Innov 4:15.

20. Joseph J, Svartberg J, Njølstad I, Schirmer H 2011 Risk factors of type 2 diabetes in groups stratified according to metabolic syndrome. A 10-year follow-up of The Tromsø Study. Eur J Epidemiol 26:117-124.

21. Mannsverk J, Wilsgaard T, Njølstad I, Hopstock LA, Løchen ML, Mathiesen EB, Thelle DS, Rasmussen K, Bønaa KH 2012 Age and gender differences in incidence and case fatality trends for myocardial infarction: a 30-year follow-up. The Tromso Study. Eur J Prev Cardiol 19:927-934.

22. Grimnes G, Joakimsen R, Figenschau Y, Torjesen PA, Almås B, Jorde R 2012 The effect of high-dose vitamin D on bone mineral density and bone turnover markers in postmenopausal women with low bone mass-a randomized controlled 1-year trial. Osteoporosis International 23:201-211.

23. Kjærgaard $M$, Waterloo $K$, Wang $C E$, Almås B, Figenschau Y, Hutchinson MS, Svartberg J, Jorde R 2012 Effect of vitamin D supplement on depression scores in people with low levels of serum 25-hydroxyvitamin D: nested case-control study and randomised clinical trial. Br J Psychiatry 201:360368.

24. Rodriguez S, Gaunt TR, Day IN 2009 Hardy-Weinberg equilibrium testing of biological ascertainment for Mendelian randomization studies. Am J Epidemiol 169:505-514.

25. Hayashi M, Matsushima K, Ohashi H, Tsunoda H, Murase S, Kawarada Y, Tanaka T 1998 Molecular cloning and characterization of human PDE8B, a novel thyroid-specific isozyme of $3^{\prime}, 5^{\prime}$-cyclic nucleotide phosphodiesterase. Biochem Biophys Res Commun 250:751-756.

26. Persani L, Borgato S, Lania A, Filopanti M, Mantovani G, Conti M, Spada A 2001 Relevant cAMP-specific phosphodiesterase isoforms in human pituitary: effect of Gs(alpha) mutations. J Clin Endocrinol Metab 86:3795-3800.

27. Vassart G, Dumont JE 1992 The thyrotropin receptor and the regulation of thyrocyte function and growth. Endocr Rev 13:596-611.

28. Wit JM, Camacho-Hübner C 2011 Endocrine regulation of longitudinal bone growth. Endocr Dev 21:30-41.

29. Monzani A, Prodam F, Rapa A, Moia S, Agarla V, Bellone S, Bona G 2012 Endocrine disorders in childhood and adolescence. Natural history of subclinical hypothyroidism in children and adolescents and potential effects of replacement therapy: a review. Eur J Endocrinol 168:R1-R11.

30. Lettre G 2009 Genetic regulation of adult stature. Curr Opin Pediatr 21:515-522.

31. Gudbjartsson DF, Walters GB, Thorleifsson G, Stefansson H, Halldorsson BV, Zusmanovich P, Sulem P, Thorlacius S, Gylfason A, Steinberg S, Helgadottir A, Ingason A, Steinthorsdottir V, Olafsdottir EJ, Olafsdottir GH, Jonsson T, Borch-Johnsen K, Hansen T, Andersen G, Jorgensen T, Pedersen O, Aben KK, Witjes JA, Swinkels DW, den Heijer M, Franke B, Verbeek AL, Becker DM, Yanek LR, Becker LC, Tryggvadottir L, Rafnar T, Gulcher J, Kiemeney LA, Kong A, Thorsteinsdottir U, Stefansson K 2008 Many sequence vari- 
ants affecting diversity of adult human height. Nat Genet 40:609-615.

32. Yang J, Benyamin B, McEvoy BP, Gordon S, Henders AK, Nyholt DR, Madden PA, Heath AC, Martin NG, Montgomery GW, Goddard ME, Visscher PM 2010 Common SNPs explain a large proportion of the heritability for human height. Nat Genet 42:565-569.

33. Gunnell D, Okasha M, Smith GD, Oliver SE, Sandhu J, Holly JM 2001 Height, leg length, and cancer risk: a systematic review. Epidemiol Rev 23:313-342.

34. Njølstad I, Arnesen E, Lund-Larsen PG 1996 Body height, cardiovascular risk factors, and risk of stroke in middle-aged men and women. A 14-year follow-up of the Finnmark Study. Circulation 94:2877-2882.

35. Jousilahti P, Tuomilehto J, Vartiainen E, Eriksson J, Puska P 2000 Relation of adult height to cause-specific and total mortality: a prospective follow-up study of 31,199 middleaged men and women in Finland. Am J Epidemiol 151:11121120.

36. Asvold BO, Bjøro T, Platou C, Vatten LJ 2012 Thyroid function and the risk of coronary heart disease: 12-year follow-up of the HUNT study in Norway. Clin Endocrinol 77:911-917.
37. Sheehan NA, Didelez V, Burton PR, Tobin MD 2008 Mendelian randomisation and causal inference in observational epidemiology. PLoS Med 5:e177.

38. Grandone A, Perrone L, Cirillo G, Di Sessa A, Corona AM, Amato A, Cresta N, Romano T, Miraglia del Giudice E 2012 Impact of phosphodiesterase 8B gene rs4704397 variation on thyroid homeostasis in childhood obesity. Eur J Endocrinol 166:255-260.

39. Klein I, Danzi S 2007 Thyroid disease and the heart. Circulation 116:1725-1735.

40. Broderstad AR, Smith-Sivertsen T, Dahl IM, Ingebretsen OC, Lund E 2010 Low prevalence of hereditary hemochromatosis in multiethnic populations in Northern Norway. Scand J Gastroenterol 46:350-357.

Address correspondence to: Rolf Jorde, $M D, P h D$ Division of Internal Medicine University Hospital of North Norway 9038 Tromsø Norway

E-mail: rolf.jorde@unn.no 